\title{
Occurrence and biodiversity of marine yeast in mangrove ecosystem of Shabi Creek, Gwadar- Pakistan
}

\author{
Irfan Ahmed ${ }^{1}$, Ameena Haroon ${ }^{1}$, Muhammad Naseem Khan ${ }^{2}$,
} Asadullah ${ }^{1}$, Hinna Shah ${ }^{1}$, Ashraf Nadeem ${ }^{1}$, Faisal Saeed ${ }^{1}$, Syed Rehmat Ullah Shah ${ }^{3}$, Muhsan Ali Abbasi ${ }^{1}$ and Muhammad Aslam Buzdar ${ }^{1 *}$

1. Faculty of Marine Sciences, Lasbela University of Agriculture, Water and Marine Sciences (LUAWMS), 90150, Uthal-Pakistan

2. Food and Marine Resources Research Centre, PCSIR Laboratories-Karachi-Pakistan

3. Department of Plant Breeding and Genetics, Faculty of Agriculture, Lasbela University of Agriculture, Water and Marine Sciences (LUAWMS), 90150, Uthal-Pakistan

*Corresponding author's email: drmaslam@hotmail.com

Citation

Irfan Ahmed, Ameena Haroon, Muhammad Naseem Khan, Asadullah, Hinna Shah, Ashraf Nadeem, Faisal Saeed, Syed Rehmat Ullah Shah, Muhsan Ali Abbasi and Muhammad Aslam Buzdar. Occurrence and biodiversity of marine yeast in mangrove ecosystem of Shabi Creek, Gwadar- Pakistan. Pure and Applied Biology. Vol. 8, Issue 1, pp680-687. http://dx.doi.org/10.19045/bspab.2019.80008

\begin{tabular}{llll}
\hline \hline Received: 10/11/2018 & Revised: 04/01/2019 & Accepted: 13/01/2019 & Online First: 18/01/2019 \\
\hline \hline
\end{tabular}

\section{Abstract}

Shabi Creek receives saline water from the west bay of Gwadar and fresh water from Ankara River and its associated watershed. In Shabi Creek only Avicennia Marina is found out of three reported species of mangrove in Pakistan. Although Pakistan's mangroves are widespread, and harbors very diverse biota has received less attention in terms of their microbial diversity particularly yeast. Marine yeasts are considered as a food source for some marine invertebrates and zooplankton and have been reported to produce useful compounds of human concern. In this study, we investigated the yeast diversity along the mangrove ecosystem of Shabi Creek, Gwadar. Yeast strains were extracted from different sections of mangrove plant such as root, stem, bark, branches, flowers, leaves, seawater, sediments, associated organisms and plants. Total 605 colonies were isolated which were further identified by their morphology and biochemical analysis and 17 distinct colonies were picked and were further analyzed by 26S rDNA gene amplicon. Sequence analysis was carried out with the help of CLC sequence viewer and the phylogenetic tree was constructed. In total 05 species of yeast were identified belonging to 04 genera i.e. Candida, Debaryomyces, Saccharomyces and Schizosaccharomyces. The identified species were Candida parapsilosis, Debaryomyces hansenii, Debaryomyces fabryii, Saccharomyces cerevisiae, Saccharomyces bayanus, Shizosaccharomyces pombe. The most dynamic growth of yeasts was observed in marine sediments among all samples. To the best of our knowledge, this is the first ever study conducted to investigate the biodiversity of mangrove ecosystem of Makran coast Gwadar, Pakistan.

Keywords: Gwadar; Mangrove ecosystem; Marine yeast diversity; Shabi Creek

\section{Introduction}

Mangrove is defined as woody plants growing in humid and sub-humid intertidal territories exposed to tidal impacts and having specially changed structurally and normal mechanisms [1]. World 60-70\% warm and partially warm coastlines are covered with mangroves, are highly 
productive ecosystems of immense ecological value. Worldwide numerous million hectares of coastal area is occupied by mangroves and distributed in over 112 countries and 1,81,000 $\mathrm{km}^{2}$ in over onefourth of the world's coastline [2].

Mangroves are a complex and dynamic ecosystem. There is also a close microbenutrient-plant mechanism to recycle and protect nutrients in the mangrove ecosystem. Microbial communities in mangrove ecosystem play a vital part in the biogeochemical cycles of shoreline networks [3].

Yeast has been isolated from both terrestrial and aquatic environment, such as river, lakes, oceans and soils [4]. Yeasts are found in the aerobic marine habitats; their species number and distribution are dependent on concentration and organic material [5].

There are many biotic and abiotic factors which highly affect yeast diversity, such as soil run-off, salinity, flora, fauna, temperature and human wastes. These conditions which prevail in the natural habitats arbiter the growth, metabolic activity and the rate of survival of the yeast populations [6].

Yeasts are reported to produce a variety of useful compounds of human concern such as ethanol, vitamins, carotenoids, glycolipids and capsular polysaccharides [7]. Besides this, some yeasts species also yield different

extra-cellular enzymes, like killer toxin and inulinase enzyme [8].

Pakistan's coastline is 1050-kilometer-long out of which $800 \mathrm{~km}$ falls under the jurisdiction of Balochistan and $250 \mathrm{~km}$ in Sindh provinces. The Balochistan coast lies between longitudes $6137^{\prime} \mathrm{E}$ and 68 12'E and latitudes $2500^{\prime} \mathrm{N}$ and $2530^{\prime} \mathrm{N}$ in the southern part of Pakistan bordering by northeast Arabian sea.

Shabi creek is a sandy cum muddy shoreline that receives saline water from the west bay of Gwatar and fresh water from Ankara River and its associated watershed. Mangrove plantation program in Shabi creek was conducted by International Union for the Conservation of Nature (IUCN) in Gwadar district since 2002 [9].

In this article, we dealt with all the yeast strains isolated from the mangrove areas of Shabi creek district Gwadar, Pakistan and tried to give a general understanding of the yeast's biodiversity of the Shabi creek mangrove.

\section{Material and methods Sampling}

Samples of root, stem, bark, leave, branches, leaves, flowers, seawater, soil and sediments along with associated flora and fauna were collected from Avicenna Marina of Shabi creek mangrove ecosystem district Gwadar $25^{\prime} 12.251 \mathrm{E}$ and $062^{\prime} 05.238 \mathrm{~N}$ (Figure 1a and $b$ ) in sterile jars and were stored in ice [10].

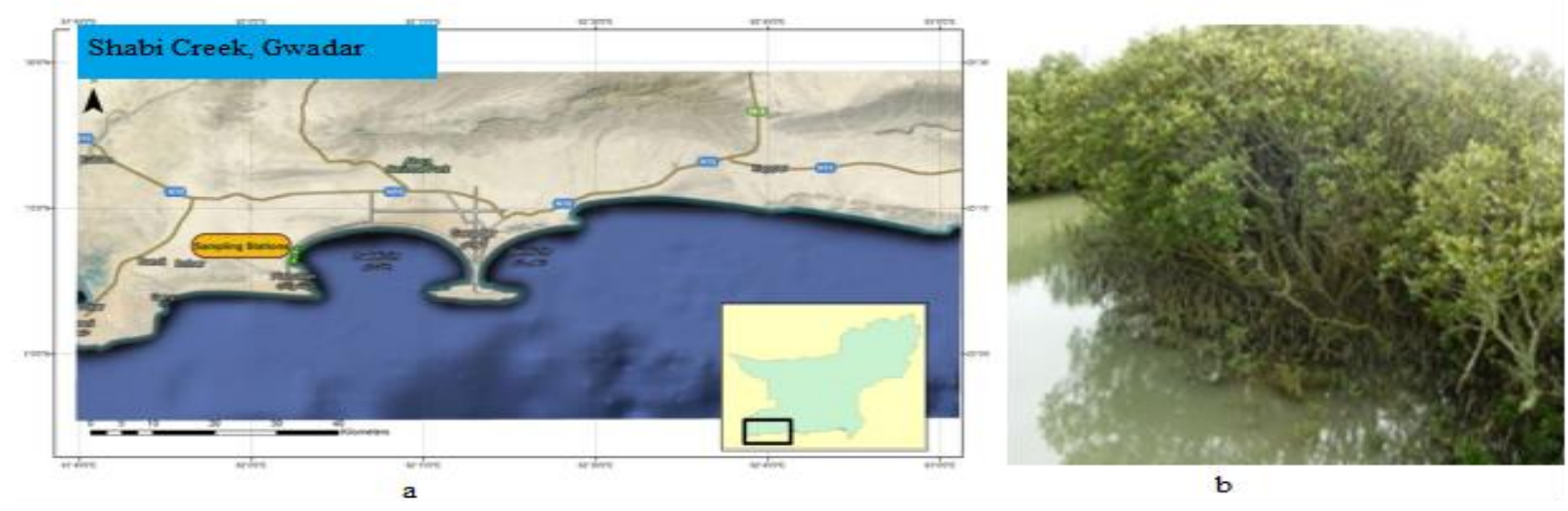

Figure 1 a) Shabi creek mangrove area and the yellow spot showing sampling site. b) Avicenna Marina 


\section{Culture media}

Yeast was cultured in YPD media which contains $20.0 \mathrm{~g}$ peptone $1^{-1}, 20.0 \mathrm{~g}$ glucose $1^{-}$ ${ }^{1}, 10.0 \mathrm{~g} 1^{-1}$ yeast extract and $15 \mathrm{~g} 1^{-1}$ agar (for solid media) supplemented with 0.05 chloramphenicol. The media was autoclaved at $115^{\circ} \mathrm{C}$ for 20 minutes [10].

\section{Yeast isolation}

10 milliliters of seawater, $10 \mathrm{~g}$ of the sediments, 10.0 of flowers, barks, roots, leaves, branches, stems of Avicenna Marina tree were immediately suspended in $90.0 \mathrm{ml}$ of saline water solution and further diluted in 5 times. $1 \mathrm{ml}$ of each dilution was spread on YPD media agar plates. The samples were incubated at $25^{\circ} \mathrm{C}$ for a week and observed on daily basis. Different colonies were isolated from each plate and streaked on separate plate to get the pure culture of each colony.

\section{Morphology identification}

Colony and cell morphology observation and fermentation tests of the yeasts were performed using standard methods [11].

\section{Preservation of yeast strain}

500ul overnight culture (YPD) of each colony was transferred into a new $2 \mathrm{ml}$ Eppendorf tube which contained $100 \mu \mathrm{l}$ (20\%) glycerol. These isolates were then stored at $-70^{\circ} \mathrm{C}$ for further use in future.

\section{DNA extraction and PCR}

Yeast isolates were grown on specific media i.e. YPD and samples were taken in $15 \mathrm{ml}$ falcon tube, centrifuged at $100 \mathrm{rpm}$, pellets were used to extract total genomic DNA [12].

Amplification and sequencing of D1/D2 26S rDNA sequences from the yeasts were performed. The common primers for amplification of D1/D2 26S rDNA in yeasts were used, the forward primer was NL-1 $\left(5^{\prime}-\right.$

GCATATCAATAAGCGGAGGAAAAG-

$\left.3^{\prime}\right)$ and the reverse primer was NL-4 (5'GGTCCGTGTTTCAAGACGG-3'),

following PCR conditions were used for primers amplification. $30 \mu \mathrm{l}$ PCR reaction was run for 30 cycles with Initial denaturation temperature $94^{\circ} \mathrm{C}$ for 4 minutes, denaturation temperature $94^{\circ} \mathrm{C}$ for $30 \mathrm{sec}$, Annealing temperature $64^{\circ} \mathrm{C}$ for 30 sec, Extension temperature $72^{\circ} \mathrm{C}$ for $45 \mathrm{sec}$, last extension temperature was set $72{ }^{\circ} \mathrm{C}$ for 10 minutes. $2 \%$ agarose gel was set up to check the amplified items. The bands were cut and purified by PCR purification kit and sent for sequencing.

\section{Taxonomic and phylogenetic analysis}

For annotation, partial 26S rDNA sequences of yeast isolates were used for taxonomic analysis the obtained sequences of yeast isolates were annotated in Basic Local Alignment Search Tool (BLAST) through NCBI database (http://www.ncbi.nlm.nih.gov/BLAST). The sequences having $\geq 96 \%$ similarity and $\geq 90$ $\%$ query coverage with the available homologous sequences in the database were thought to be the same species.

Top two homologues of $26 \mathrm{~S}$ rDNA were selected and aligned with sequences of yeast isolates and uneven ends were trimmed at 5' and 3 ' ends to get identical positions using CLC sequence viewer (www.qiagenbioinformatics.com).

Phylogenetic analysis was performed through the Neighbor-Joining method with bootstrap values of 100 replicates using default parameters.

\section{Result and discussion}

Isolation and morphological identification of yeast strains

Total 605 colonies were initially isolated from all samples i.e. roots, stem, bark, leaves, flowers, sediments, seawater and associated flora and fauna of mangroves of Shabi creek. Purification of all colonies was performed between 5-7 day. This incubation time was set in order to get satisfactory growth of yeast colony but to avoid contamination of filamentous fungi. These colonies were further analyzed on the basis 
of colony shape, size, color and texture by getting the pure colony. Total 17 individual yeast strains having different morphological characteristic were selected from original yeast agar plates to be further analyzed by 26S rDNA gene amplicon.

\section{Taxonomic identification}

For taxonomic identification, the 26S rDNA sequences was annotated through blast analysis. The annotation of sequences through BLAST analysis revealed that the yeasts strains are comprised of five species i.e. Candida parapsilosis, Debaryomyces fabryii, Debaryomyces hansenii, Saccharomyces cerevisiae, Shizosaccharomyces pombe belonging to four different genera (Table 1). Each of the species showed around $90 \%$ similarity with the top hit of available data in NCBI. The query coverage was observed more than 95\% against each sequence.

Table 1. Taxonomic Identification

\begin{tabular}{|c|c|c|c|}
\hline \multirow{2}{*}{ No. } & Yeast Strain & Species & \multirow{2}{*}{ Identity (\%) } \\
\cline { 2 - 4 } & No & (Gene bank Accession No) & 99 \\
\hline 1 & IY1 & Saccharomyces bayanus (X97777.1) & 99 \\
\hline 2 & & Saccharomyces cerevisiae (NR_132213.1) & 100 \\
\hline 3 & IY2 & Candida parapsilosis (AY05857.1) & 99 \\
\hline 4 & & Candida parapsilosis (FJ538165.1) & 99 \\
\hline 5 & IY3 & Schizosaccharomyces pombe (NM_001019106.2) & 97 \\
\hline 6 & & Schizosaccharomyces Octospurus (XM.013165169) & 100 \\
\hline 7 & IY4 & Debaryomyces fabryi (XM_015612932.1) & 100 \\
\hline 8 & & Debaryomyces hansenii (XM_459191.1) \\
\hline 9 & IY5 & Candida sp (XM_018312081.1) & 100 \\
\hline
\end{tabular}

\section{Phylogenetic analysis}

Phylogenetic analysis of the 26S rDNA sequences of yeast including top two identical sequences retrieved from NCBI database showed that the yeast isolates are first grouped into three major clads with a further division of each clad into two groups except the Candida sp. which was places in a separate phylogenetic branch. At the tip of the branches, all the five isolates are placed in five separate groups (1-5) with bootstrap value of 100. Regardless the phenetic distribution of different genera, the two species: IY2 and IY5 of the genus Candida are placed in group 1 and 5 sharing the group with Candida parapsilosis and Candida $s p$ respectively, the two species of genus Saccharomyces i.e. IY1 and IY3 are placed in group 2 and group 3, sharing the group with Saccharomyces cerevisiae and Shizosaccharomyces pombe respectively and the genus Debaryomyces has a single species IY4 which is present in group 4 with Debaryomyces fabryii. The phylogenetic distance among the yeast species within the genera indicates the discrepancy between phylogenetic and phonetic taxonomy. The Inconsistency between molecular and phenetic taxonomy in yeast was also reported previously [13].

Genus candida, phylum Ascomycota has been reported as a prevalent genus among other in the marine environment we also isolate two species of candida and our data revealed that $40 \%$ of the identified yeast species belonged to candida. The twocandida species were identified by both morphologically and by molecular phylogenetical analysis which were found abundantly (40\%) among all the culturable isolates of yeasts strains (Figure 2). 


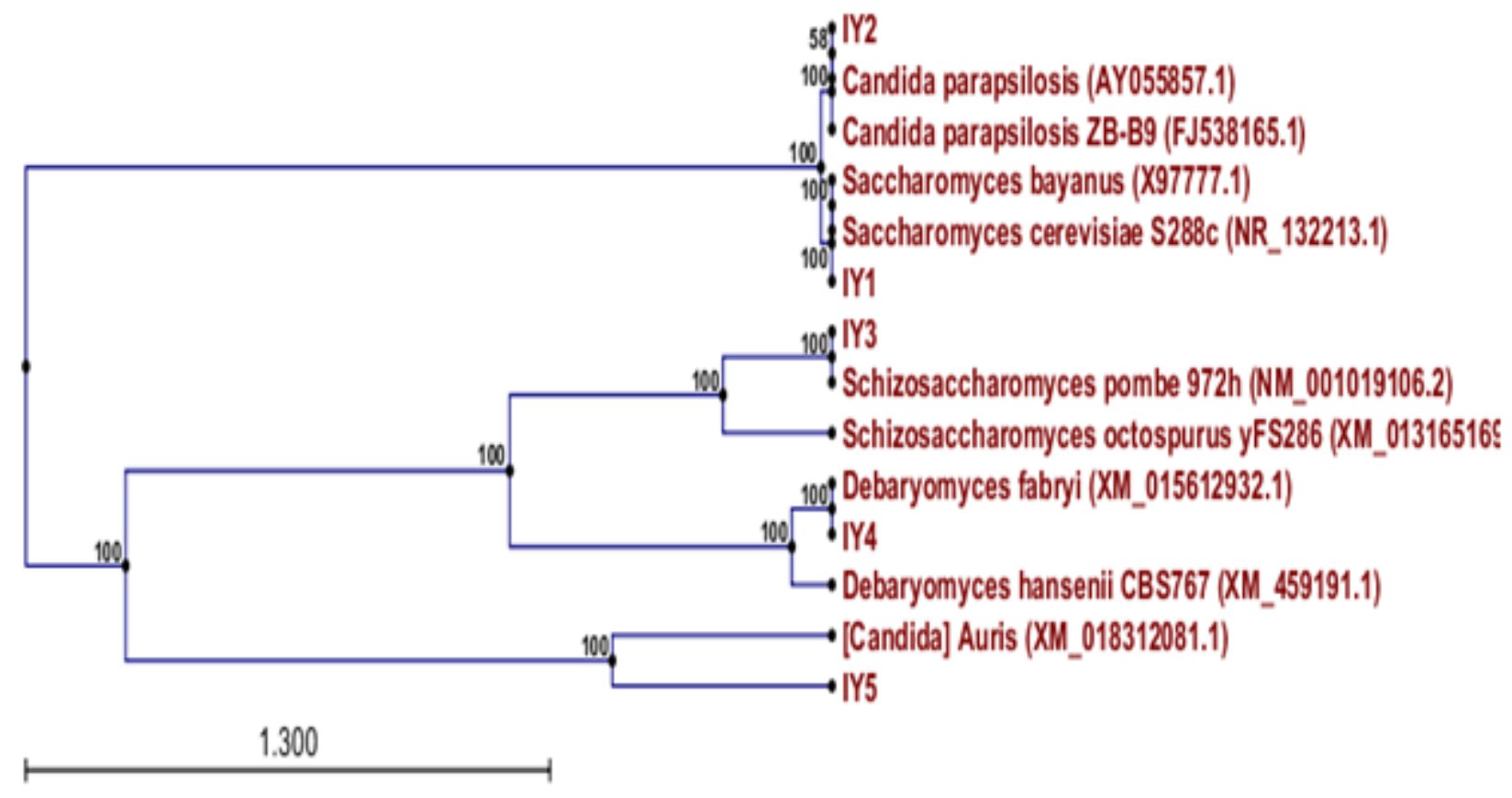

Figure 2. Phylogenetical analysis of amplified partial sequences of $26 \mathrm{~S}$ rDNA from Yeast species Isolated from Mangrove ecosystem. Sequences top 2 hits of blast analysis of 26S rDNA were used to make comparisons. The phylogenetic tree was constructed on aligned sequence using the Neighbor-Joining method and bootstrapping of 100 replicates, Isolates are represented by "IY-numbers" while related species are presented by their names followed by accession numbers.

Morphologically candida parapsilosis colony found white, creamy and shiny having oval, round or cylindrical cell shape. It does not have true hyphae but pseudo hyphae. This is considered as more naturally occurring specie [14]. Candida sp. and candida parapsilosis were isolated from stem, leaves, roots, crabs, shell, sediments and mud. (Table 2)

Two species of genus Debaryomyces were identified i.e. Debaryomyces hansenii which has colony greyish-white to yellowish colony with spheroidal to ovoidal of shape. D. hansenii was previously isolated from mangrove ecosystem of China [15]. The D. hansenii is osmotolerant and can grow at $10 \% \mathrm{NaCl}$ or $5 \%$ glucose. It has also been reported to produce a variety of biotechnological compounds and found resistant to many killer toxins [16]. On the other side compared to $D$. fabryii with $D$. hansenii has the ability to grow at $36^{\circ} \mathrm{C}$ to $39^{\circ} \mathrm{C}$ and is more resistant to oxidative stress [17] and mostly isolated from human skin infection [18]. The data from the current study revealed that the mangrove ecosystem of Shabi creek exhibits 20\% Debaryomyces (Figure 3). The strain from genus Debaryomyces were isolated from mangrove's leaves, bark and mud. 
Table 2. Morphological analysis of yeast isolated from Shabi creek

\begin{tabular}{|c|c|c|c|c|c|}
\hline Origin & Color & Shape & Size & Possible genera & $\begin{array}{c}\text { Assigned } \\
\text { codes }\end{array}$ \\
\hline Shell, and leaves and flowers & White & Circular & Large & Saccharomyces & IY1 \\
\hline $\begin{array}{c}\text { sediment, } \\
\text { Stem and roots, crabs and }\end{array}$ & $\begin{array}{c}\text { White creamy } \\
\text { shining }\end{array}$ & Oval & Large & Candida & IY2 \\
\hline $\begin{array}{c}\text { Sediment, sea water and } \\
\text { roots }\end{array}$ & White & Circular & Large & $\begin{array}{c}\text { Schizosaccharo } \\
\text { myces }\end{array}$ & IY3 \\
\hline Leaves and barks, mud, & White & Spherical & Small & Debaryomyces & IY4 \\
\hline Leaves and barks, mud, & White & Spherical & Small & Debaryomyces & IY4 \\
\hline Shell & Yellow & Filamentous & Large & Candida & IY5 \\
\hline
\end{tabular}

N. Jayalakshmi and his colleague G. Umamaheshwari isolated Saccharomyces cerevisiae from Muthupet mangrove environment and sea water of Thailand in 2016 [18]. Obara and his colleagues [19] used $S$. cerevisiae for the ethanol production while few other researchers [20] isolated Saccharomyces bayanus from the marine environment and tested its hydrocarbon degradation in the presence of organic solvent. They also isolated few species of genus Schizosaccharomyces i.e. S. pombe from marine environment and was them tested against hydrocarbon degradation in the presence of organic solvent.

Our present data revealed that the mangrove ecosystem of Shabi creek district Gwadar, Pakistan was comprised of $20 \%$ Saccharomyces and Schizosaccharomyces each (Figure 3) We isolated yeasts strains belonging to genera Saccharomyces and Schizosaccharomyces were isolated from leaves, flowers, shell and root, sediment and seawater respectively.

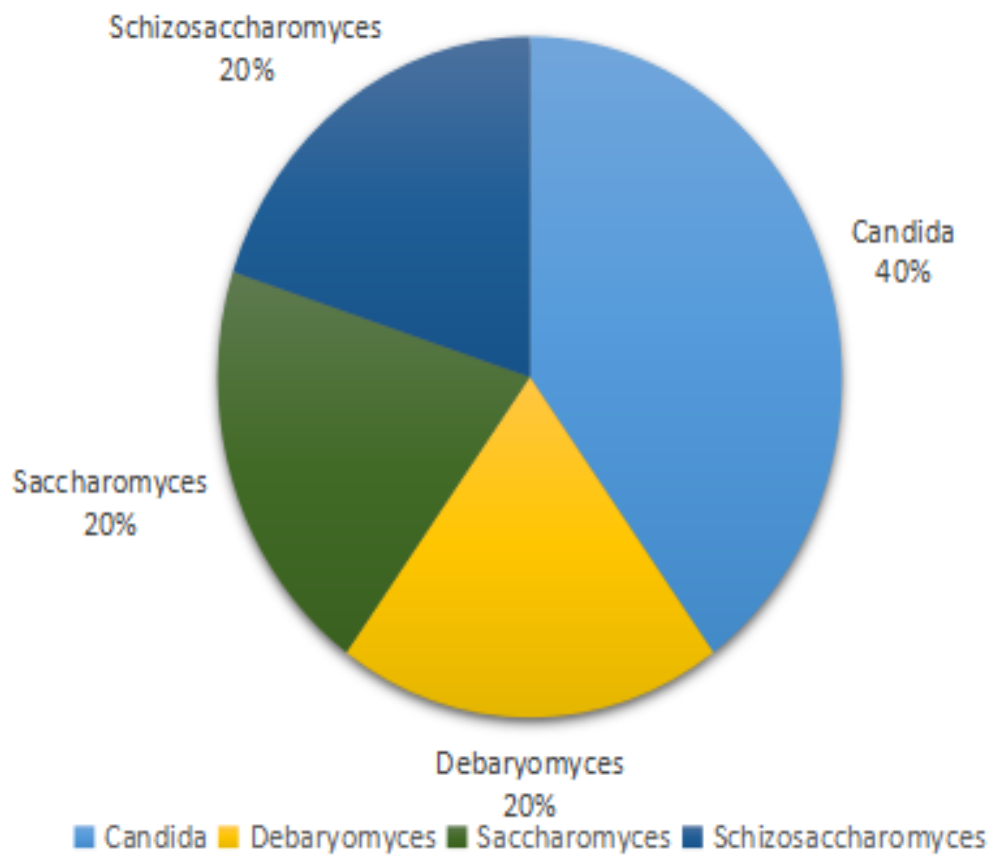

Figure 3. Chart depicting the percentage of isolated genera of marine yeasts from mangrove ecosystem of Shabi creek, Gwadar 


\section{Conclusion}

The literature cited showed that research on marine yeasts in Pakistan is comparatively less and poorly studied. Marine yeasts are of great importance having amazing biochemical characteristics used in industries and naturally in the environment to make it clean as a biological cleaner to ocean waters having oil spills and pollution from other resources. The objective of this investigation was to find out the availability of marine yeasts in the mangrove ecosystem and to check the specie richness (Shabi creek) our data is in the line of the previous reports on the diverse of marine yeasts in the mangrove ecosystem worldwide However it is recommended that the isolated yeasts may further be exploited in terms their biotechnological potentials for the welfare of mankind.

\section{Authors' contributions}

Conceived and designed the experiments: MA Abbasi \& MA Buzdar, Performed the experiments: I Ahmed, A Haroon, Asadullah, H Shah, A Nadeem \& F Saeed, Analyzed the data: I Ahmed, A Haroon \& SR Shah, Contributed materials/ analysis/ tools: I Ahmed, Asadullah, H Shah \& MN Khan, Wrote the paper: SR Shah \& MA Buzdar.

\section{Acknowledgement}

We are thankful to Higher Education Commission of Pakistan for providing funds under the Project No\# 2950 under National Research Program for Universities (NRPU).

\section{References}

1. Hogarth PJ (2015). The biology of mangroves and seagrasses. Oxford University Press.

2. Spalding MD, Blasco $\mathrm{F} \&$ Field $\mathrm{CD}$ (1997). World Mangrove Atlas.

3. Dittmar T \& Lara RJ (2001). Do mangroves rather than rivers provide nutrients to coastal environments south of the Amazon River? Evidence from long-term flux measurements. Marine Ecol Prog Series 213: 67-77.

4. Uden NV (1960). The occurrence of Candida and other yeasts in the intestinal tracts of animals. Annals of the New York Acad of Sci 89(1): 59-68.

5. Fell JW (2001). Collection and identification of marine yeasts. Methods in Microbiol 30: 347-356.

6. Deak T (2006). Environmental factors influencing yeasts. In: Biodiversity and ecophysiology of yeasts. Springer pp 155-174.

7. Demain A, Phaff $\mathrm{H}$ \& Kurtzman $\mathrm{C}$ (1998). The industrial and agricultural significance of yeasts. In: The Yeasts (Fourth Edition). Elsevier pp 13-19.

8. Chi Z, Chi Z, Zhang T, Liu G \& Yue L (2009). Inulinase-expressing microorganisms and applications of inulinases. Appl Microbiol and Biotechnol 82(2): 211-220.

9. Qureshi T (2005). Mangroves of Pakistan: status and management. IUCN Pakistan.

10. Buzdar MA, Chi Z, Wang Q, Hua M-X \& Chi Z-M (2011). Production, purification, and characterization of a novel killer toxin from Kluyveromyces siamensis against a pathogenic yeast in crab. Appl Microbiol and Biotechnol 91(6): 1571-1579.

11. Kurtzman CP \& Robnett CJ (1998). Identification and phylogeny of ascomycetous yeasts from analysis of nuclear large subunit (26S) ribosomal DNA partial sequences. Antonie van Leeuwenhoek 73(4): 331-371.

12. Sambrook J, Fritsch EF \& Maniatis $\mathrm{T}$ (1989). Molecular cloning: a laboratory manual. Vol Ed. 2. Cold spring harbor laboratory press.

13. De Barros Lopes M, Soden A, Martens AL, Henschke PA \& Langridge P (1998). Differentiation and species 
identification of yeasts using PCR. Inter $J$ of Syst Bacteriol 48 (Pt-1): 279-286.

14. Kuhn DM, Mukherjee PK, Clark TA, Pujol C, Chandra J, Hajjeh RA, Warnock DW, Soll DR \& Ghannoum MA (2004). Candida parapsilosis characterization in an outbreak setting. Emer Infec Dis 10(6): 1074.

15. Chi Z-M, Liu T-T, Chi Z, Liu G-L \& Wang Z-P (2012). Occurrence and diversity of yeasts in the mangrove ecosystems in Fujian, Guangdong and Hainan Provinces of China. Indian $J$ of Microbiol 52(3): 346-353.

16. Breuer U \& Harms H (2006). Debaryomyces hansenii-an extremophilic yeast with biotechnological potential. Yeast 23(6): 415-437.
17. Nakase T \& Suzuki M (1985). Taxonomic Studies on Debaryomyces Hansenii (Zopf) Lodder Et Kreger-Van Rij And Related Species. The $J$ of General and Appl Microbiol 31(1): 4969.

18. Suzuki M, Prasad GS \& Kurtzman CP (2010). Debaryomyces Lodder \& kreger-van rij (1952). In: The Yeasts (Fifth Edition). Elsevier, pp 361-372.

19. N. Jayalakshmi GU (2016). Isolation of Marine Yeast from Muthupet Mangrove Environment. Inter $J$ of Pharm and Pharma Res 6(4): 200-205.

20. Obara N, Ishida M, Hamada-Sato N \& Urano N (2012). Efficient bioethanol production from paper shredder scrap by a marine derived Saccharomyces cerevisiae C-19. Stud in Sci and Technol 1(2): 127-132. 